\title{
TLC con Estados Unidos y los argumentos de legitimación de la oligarquía colombiana
}

\author{
The FTA With The United States And The Arguments Of Legitimation Of The Colombian Oligarchy \\ Sandra Milena Polo Buitrago \\ Universidad Distrital-Bogotá, Colombia \\ sanpo31@hotmail.com \\ DOI: https://doi.org/10.24215/15155994e148 \\ Redalyc: http://www.redalyc.org/articulo.oa?id=84563515010
}

Recepción: 09 Abril 2019

Aprobación: 05 Marzo 2020

\section{Resumen:}

Este artículo examina los discursos de justificación del TLC entre Colombia y Estados Unidos, proferidos por representantes de la actual oligarquía colombiana cercanos al proceso. El objetivo del análisis es mostrar que tales justificaciones tecnocráticas encubren la decisión política de conceder privilegios a los Estados Unidos y afianzar los privilegios de, entre otros, un sector de la oligarquía agraria. Metodológicamente asume el análisis del discurso entendiendo este como un código semiótico en función de los intereses de un grupo, y por tanto productor de sintagmas que pretenden avalar una ideología con un propósito definido. En este caso cierta ideología liberal que tiende a legitimar la impotencia tecnológica como desidia ética de los gremios económicos; y, a su vez, se presenta, veladamente, la cadena productiva del agrocultivo como la solución a esta impotencia tecnológica. De la misma forma, el discurso del aprovechamiento técnico-pedagógico de las oportunidades de demanda externa, legitima la dedicación del agrocultivo a productos exóticos fuera de la órbita competitiva de los Estados Unidos, cediendo a éste la potestad sobre los cultivos fundamentales para la soberanía alimentaria.

Palabras clave: TLC, Estados Unidos, Colombia, Oligarquía, Ideología, Soberanía alimentaria.

\begin{abstract}
:
This paper is an essay on the speeches for justifying the FTA between the United States and Colombia, as uttered by outstanding representatives of the Colombian ruling class deeply engaged into that agreement process. The aim of this analysis is to point out the vanished political decision of giving privileges to the United States, besides reinforcing the already acquired privileges of a certain group into the very Colombian oligarchy. Methodologically it assumes the analysis of the discourse, understanding it as a semiotic code based on the interests of a group, and therefore producer of phrases that seek to endorse an ideology with a defined purpose. In this case a certain liberal ideology that tries to legitimate the technological powerlessness of the Colombian economy, and, besides, mask the agribusiness like the solution to such a powerlessness. In likewise manner, this paper aims to present the speech on the pedagogic-technical seizing of the foreign demand opportunities, does legitimate the orientation of the agribusiness towards the tropical fruits production, by leaving the basic feed for the food sovereignty under the United States control.
\end{abstract}

KEYWORDS: FTA, United States, Colombia, Oligarchy, Ideology.

\section{El PROBlema y EL MÉTODo *}

Desde el año 1994, Colombia ha venido celebrando acuerdos comerciales en el contexto del modelo económico de apertura; de acuerdo con información del Ministerio de Industria y Turismo, hay catorce acuerdos comerciales vigentes (MINCIT, 2019). De todos estos acuerdos comerciales, el más controversial ha sido, hasta el momento, el Tratado de Libre Comercio (TLC) firmado con Estados Unidos; el carácter controversial de este acuerdo se debe a las condiciones que implica: es un tratado que se comenzó a negociar desde el 18 de mayo de 2004 en la ciudad de Cartagena y se firmó el 22 de noviembre de 2006; no obstante, sólo entró en vigencia el 14 de mayo de 2012. Esta extensión en el tiempo, de seis años, se debió a que, para aprobarlo, por parte del legislativo de los Estados Unidos, surgieron dificultades. (Espinosa y Pasculli, 2013). Al parecer, las quejas se referían a la violencia contra los líderes de los sindicatos en Colombia y a temas medioambientales, situación que se resolvió, en 2011, con un acuerdo firmado, en abril, entre los 
presidentes Barack Obama, de los Estados Unidos y Juan Manuel Santos de Colombia. El acuerdo se aprobó, en el Congreso de los Estados Unidos, el 12 de octubre de 2011, y la ley aprobatoria fue sancionada, por Obama, el 21 de octubre del mismo año. Luego, en la contraparte colombiana, correspondió perfeccionar 11 disposiciones adicionales, para llegar a un total de 69 disposiciones, que requerían la elaboración de una serie de leyes y actos legislativos que, finalmente, se aprobaron ante la solicitud, de trámite con urgencia, del gobierno colombiano al Congreso; dicho respaldo lo logró el ejecutivo gracias a la Bancada de la Unión Nacional, conformada por el Partido Cambio Radical, el Partido de la U y el Partido Liberal. (Espinosa y Pasculli, 2013, p. 52)

En general, el Tratado de Libre Comercio, suscrito entre los gobiernos de Colombia y los Estados Unidos, es un tratado - por decirlo menos- bastante oneroso y desigual. Los elementos para probar esta afirmación son:

1. No se tuvo en cuenta el único producto colombiano realmente competitivo a nivel internacional: el azúcar, lo cual demuestra que Estados Unidos manejaba la negociación y no Colombia.

2. Estados Unidos no eliminó la ayuda interna a su producción agraria; en cambio, Colombia se retiró del sistema andino de franjas de precios (SAFP) y del mecanismo de administración de contingentes (MAC), que garantizaban la compra de cosechas nacionales.

3. Los productos colombianos exportados a los Estados Unidos, en su mayoría, ya contaban con entrada libre de aranceles antes del Tratado, es decir, para Colombia no hubo, desde un principio, ventajas adicionales con el TLC.

4. Los productos que el gobierno colombiano llamó "promisorios", en el TLC con Estados Unidos, son inciertos, dado que su producción depende tanto del cumplimiento de condiciones internas (impulso y apoyo a su producción por parte del Estado colombiano), como de la voluntad de las autoridades estadounidenses para remover barreras arancelarias y normas sanitarias y fitosanitarias impuestas por EEUU ${ }^{1}$. Esto sin contar con la inversión de capital fijo que se requiere para hacer adecuaciones y a las que no es fácil que se adapte la economía de los pequeños campesinos.

5. Las economías de Colombia y Estados Unidos son asimétricas, con la clara ventaja de este último. Esta situación se puede ilustrar con algunos indicadores en términos de PIB total en 2001: la economía estadounidense es 122 veces más grande que la colombiana, con una población 7 veces mayor, un ingreso PIB per cápita 18 veces superior y un PIB agropecuario 15 veces mayor que el colombiano, además de un gran potencial exportador, pues Estados Unidos es el mayor productor mundial de carnes de aves y de res; además de maíz, sorgo, soya, torta de soya y aceite de soya; $y$, también, es el segundo productor mundial de carne de cerdo, leche, huevos, miel y algodón; y el cuarto productor mundial de trigo, papa y tabaco. En cambio, Colombia no es el mayor productor ni exportador mundial de ningún producto agropecuario de importancia en el comercio mundial 2 (Garay, Barbieri y Cardona, 2010, p. 15).

Una pregunta posible es: ¿Por qué se firma un TLC en estas condiciones? La firma de un tratado de esta naturaleza es una decisión económica y política; y esta decisión está motivada por una serie de condiciones, objetivas. La firma de Tratados de Libre Comercio es una política pública en Colombia, para el desarrollo de la cual se han creado instituciones como la Oficina de Aprovechamiento de los TLC. Ahora bien, para suscribir un acuerdo comercial tan peculiar como el suscrito con Estados Unidos, se requiere tanto una comprensión de la situación, por parte de las oligarquías que controlan el Estado, como, al mismo tiempo, unos objetivos, es decir, unos resultados que se esperan de esta decisión.

Como lo ha demostrado Estrada (2006), el proceso de neoliberalización de la economía, el derecho, la política y la administración, en fin, del Estado colombiano, que arrancó su marcha, formal y abiertamente, a partir de la constitución política de 1991, y que ha alcanzado en la firma del TLC con Estados Unidos uno de sus hitos más importantes, este proceso es la instanciación local, de una tendencia global del capitalismo 
a nivel mundial. Una tendencia implica, de alguna manera, un consenso, una especie de acuerdo, tácito o explícito, sobre los principios generales que posibilitan la constitución del comportamiento tendencial; sin embargo, el consenso - como lo afirmara Villoro (1982) - no implica, necesariamente, la verdad de la creencia sobre la que surge el consenso. En la medida en que la firma de TLC, entre diversos Estados, sea una tendencia, en esa medida, tal tendencia implica una creencia; de hecho, así pareciera darlo a entender, al menos, Dillon (1995, p. 279): la creencia implícita, aparentemente, en la idea de un tratado de libre comercio - según nos dice Dillon - es la creencia en una ganancia recíproca para las dos partes tratantes; ésta es una creencia, añade Dillon, emergida en la Economía política clásica, la de Ricardo. Por supuesto, tal creencia - aclara Dillon - no ha dejado de tener sus críticos dentro de la propia ciencia económica y dentro de la historia económica: dentro de la ciencia de la economía refiere, entre otros, al propio Maynard Keynes como uno de los críticos. Ahora bien, el mismo Dillon hace esta afirmación:

La historia nos enseña que el comercio entre naciones puede producir ganancias mutuas. Pero el libre comercio no necesariamente produce ganancias similares para todos los participantes en una zona de libre comercio, especialmente cuando existen grandes asimetrías entre los participantes. Las ganancias del comercio pueden ser mal distribuidas entre países, entre regiones o entre grupos sociales. (Dillon, 1995, p. 280)

Así, pues, Dillon mismo cree en las ventajas recíprocas del libre comercio entre países, aunque, por supuesto la medida y naturaleza de estas ventajas depende de factores contextuales, entre ellos la asimetría entre las partes, como ocurre, por ejemplo, en el caso del TLC entre Colombia y Estados Unidos. Esto significa que, en la medida en que se trata de un ejercicio de reciprocidad entre partes, un ejercicio de mercado, las ventajas que se obtengan en este ejercicio dependen de la negociación, pues el libre comercio es un asunto de negocios. El TLC, se refiere a tratados de negocios mercantiles cuyo éxito o fracaso depende de las decisiones de individuos, en este caso, representantes de Estados territoriales, o sea, políticos y tecnócratas que, comprometidos con un gobierno, llevan la vocería de éste como portavoces de su capacidad y sabiduría en ese asunto relativo a las reglas y tratados económicos, en el contexto del capital mundial.

El consenso no implica, necesariamente, la verdad de la creencia que lo sostiene, esto sucede en el caso de los TLC; ya que la verdad del beneficio, de principio, para las partes comprometidas en el Tratado, realmente depende de la capacidad de negociación, y ésta es un saber pragmático que bien puede estar derivado de teorías económicas o jurídicas, pero que, en últimas, depende de la habilidad para instrumentalizarlas. No es, pues, una verdad a priori, sino a posteriori; no es un datum sino un constructum: la capacidad negociadora, y la asesoría de tecnócratas, es fundamental en este tipo de procesos. Las oligarquías han estado, en Colombia, siempre asesoradas por tecnócratas, al menos las de la generación que ha implementado el neoliberalismo, o sea, las de los últimos treinta y siete años. Según Puello y Estrada (2005, p. 111), aunque es poca, la literatura sobre el tema ha permitido contextualizar la participación de economistas en la era neoliberal, su paulatina preeminencia sobre los abogados y, además, la participación de dirigentes gremiales en la conformación paulatina de una élite intelectual que orienta las decisiones de los gobiernos en el contexto de la neoliberalización. Por supuesto, hemos de suponer, en estos economistas, la creencia en la verdad sobre el libre comercio, es decir, la verdad de los mutuos beneficios entre las partes; ahora bien, las cinco condiciones en las que Colombia firmó el TLC con Estados Unidos, enumeradas al comienzo muestran totalmente las desventajas en que Colombia firmó dicho tratado.

Decir Colombia es tanto como decir, la oligarquia colombiana. Precisando nuestros conceptos, hemos de hacer un corto excurso: se emplea el término oligarquía para referir una la clase que tiene el poder permanente de hacerse con el control del Estado. En la sociología sobre los estudios relativos a esta clase, se suele emplear el término élite, término de origen anglosajón. Sin embargo, aquí preferimos oligarquia por razones etimológicas: la clase dominante la concebimos como aquella clase social que tiene el poder de controlar las fuerzas productivas, los medios de producción; pero esa clase no es homogénea, por supuesto, en su seno, hay distinciones y aun fracturas; y, entre esas distinciones, está la de aquel sector cuyo desarrollo se da en función del control del poder estatal a partir del desarrollo de las justas políticas para acceder a ese 
control. La oligarquía es una clase selecta, una categoría de exclusividad: en griego clásico oligos, adjetivo que significa escaso, poco, pequeño; y arkhe, que significa principio, mando, gobierno, poder. La oligarkhia es el gobierno de los pocos, un substantivo que, en su aurora griega, mentaba una posibilidad de gobierno, no una clase social. El asunto es que, hoy, esos pocos que tienen acceso a esa forma de gobierno sí conforman, efectivamente, una clase que se apropia enteramente esa forma de gobierno. De ahí que, en la modernidad, la oligarquía termine mencionando una clase, un sector de una clase social, de la clase dominante, un sector exclusivo de la burguesía. Emplearemos los términos oligarquía y burguesía como sinónimos, en el entendido en que la oligarquía sólo puede ser un sector de la burguesía, el que tiene el control efectivo del poder estatal.

Regresando a nuestro asunto directo, preguntamos: ¿Qué gana realmente con ese tratado este sector de la clase dominante en Colombia? Algo deben estar ganando como élite, como oligarquía, aunque en el negocio representen a toda una nación, incluyendo los campesinos que pierden con el desarrollo del Tratado, ya que al firmarse se acepta la entrada de productos estadounidenses que se producían en Colombia vgr, lácteos, cereales, oleaginosas (Suárez, 2015a). Ensayaremos aquí, para dar una respuesta, una arista rápida de abordar en poco espacio: el discurso legitimatorio de su decisión a seis años de haberse celebrado el negocio ¿̇or qué el discurso? Porque fue una decisión, un acto de decisión, cuyas bondades prometidas, no realizadas aún, sólo se pueden justificar discursivamente. Aún se pueden escuchar y leer declaraciones de estos tecnócratas y políticos sosteniendo esas bondades que no se hacen manifiestas; y este contraste entre los hechos y las palabras nos autoriza a pensar que estamos ante un fenómeno ideológico.

Por consiguiente, es ese viejo lema de la Ideología Alemana: las ideas de una época son las ideas de su clase dominante (Marx y Engels, 1987, p. 50 - 51). Vale la pena recordar este principio teórico porque permite poner en relación las ideas y el poder material dominante, en este caso concreto, las relaciones sociales dominantes, en relación con la producción agraria. En la situación problémica descrita atrás, a saber, un TLC oneroso y desventajoso para un país, es, no obstante, firmado por la clase dominante de ese país, en esta situación, esto indica que esa élite desoye, totalmente, lo que afirman sus científicos, sus académicos, respecto del asunto, justamente, en el contexto de un ambiente espiritual en el que se afirman lemas (impulsados y esgrimidos en otras ocasiones por esa misma élite) como el de que la época actual es la época de la sociedad del conocimiento. Si el conocimiento no le interesa para la firma de un tratado como el TLC, en condiciones claramente onerosas, es porque lo que se entendería, en este caso, como el "interés nacional" tiene un significado esotérico que sólo lo entienden los miembros de esta élite e, incluso, aquellos comprometidos directamente en la negociación. Ignorar el saber genuino para tomar una decisión tan cara, implica que lo que se juega en esa decisión choca, de plano, con lo que afirma ese saber, y esto sólo ocurre cuando se enfrentan el saber con el deseo, lo objetivo con lo subjetivo. Estamos, pues, ante intereses inconfesables públicamente, pero que se ocultan tras algún disfraz ideológico; es por esto que, la respuesta a la pregunta inicial de este escrito ha de depender de una teoría de la ideología.

Como dice Villoro (1985), el concepto de ideología tiene dos aspectos: uno (1) gnoseológico, relativo a la consistencia argumental de los enunciados; y otro (2) sociológico relativo al interés político mistificado tras ese conjunto de enunciados. Este ejercicio va del primero al segundo, o sea, del análisis de los enunciados al interés político mistificado en ellos. Este sentido del recorrido, de 1 a 2, constituirá una explicación de lo primero por lo segundo: en este caso, la persistencia en pactar un trato oneroso, a sabiendas, sólo puede tener una explicación política.

La ideología, o sea, el conjunto de enunciados que expresan las creencias de la clase dominante, y que permiten la promoción de su poder, tiene como medio concreto de circulación, el ámbito de la opinión pública; ésta es un efecto discursivo creado a partir de dispositivos de comunicación para masas: radio, televisión, prensa escrita, internet. Pero la opinión pública, es decir, este efecto mediático, consiste en la propagación, por los medios de comunicación, de conjuntos de enunciados de uso común que, permanentemente, moldean una opinión promedio, en determinados contextos de comunicación social. De esta forma, cuando hemos de pensar en la ideología, concretamente, pensamos en esos grupos de enunciados 
que circulan en los medios mencionados. Se utilizan aquí, , secciones de revistas y periódicos y videos de internet, instrumentos de expresión de dicha ideología.

\section{OligarQuía COLOMBIANA: RASgOS GENERALES ACTUALES}

La oligarquía es ese sector reducido de la clase dominante que tiende a monopolizar el control directo del poder político y el Estado. En Colombia, podemos mencionar ese sector de su burguesía como oligarquía, una burguesía especializada en el control directo del Estado, a tal punto que son identificables apellidos de linajes familiares, a lo largo de todo el siglo XX hasta hoy: Holguín, Ospina, Santos, Lleras, López, Samper, Pastrana, Galán, Uribe, apellidos ligados al establecimiento del poder político y económico ${ }^{3}$. En esta sucesión de linajes oligárquicos, cabe poner como ejemplo paradigmático, el caso de la familia López ya que dos de sus miembros fueron muy importantes para la política del siglo XX en Colombia: Alfonso López Pumarejo, presidente en dos períodos: entre 1934-1938 y 1942-1945 (fue destituido un año antes de concluir el segundo período), considerado como uno de los grandes estadistas del siglo XX en Colombia, artífice del proceso modernizador en el inicio del modelo de sustitución de importaciones. Su hijo, Alfonso López Michelsen, presidente entre 1974 y 1978, cuyas reformas son el comienzo del fin del modelo de sustitución de importaciones; entre ambos puede decirse que se debate la esencia política del siglo XX en Colombia.

Ahora bien, la oligarquía es la punta de lanza de la clase dominante. En las justificaciones de las dificultades que presenta el TLC para Colombia, en tanto un Tratado entre partes desiguales, en condiciones asimétricas la una respecto de la otra, la oligarquía mistifica, en el control mediático y de la opinión pública, el hecho de que sus intereses básicos han sido afianzarse en el contexto de la reorganización de la economía que se dio desde el fin del Frente Nacional. Un largo y lento proceso de más de cuarenta años, proceso que consistió en integrar la economía nacional a la internacional. Estrada (2006) describe, con relativa minucia, la forma en que se dio una reorganización jurídico-administrativa en campos estratégicos del desarrollo social, para lograr este objetivo, que se inició hace más de cuarenta años, como efecto del fin del modelo de sustitución de importaciones. El TLC es el logro más alto de este largo proceso; pero - como ha sido evidente hasta el presente - ha sido un logro mediocre, que no ha traído hasta la actualidad mayores beneficios a la economía colombiana.

Durante la primera mitad del siglo XX, las oligarquías hacendatarias en el poder se constituyeron, gracias a la bonanza cafetera, en una burguesía que propició las inversiones para la modernización industrial, dentro del contexto del modelo de sustitución de importaciones. Pero el fin del modelo sustitutivo obligó a las clases dominantes, en particular a las oligarquías, a tomar nuevas decisiones: Libreros y Sarmiento (2007) nos refieren este principio del nuevo proceso de reorganización de esta clase en el último gobierno del Frente Nacional ${ }^{4}$. Un rasgo de las oligarquías colombianas, un rasgo permanente, por lo menos desde el fin de la hegemonía conservadora, en los años treinta del siglo XX, ha sido su dependencia de los gobiernos estadounidenses, en materia de orientación del ejercicio de su poder. Esta dependencia, por supuesto, está ligada a concesiones a los intereses de las oligarquías estadounidenses. Como lo demostrara Hegel, en la Fenomenología del Espíritu, la dialéctica del amo y el esclavo implica el reconocimiento mutuo de las partes implicadas en esa relación; y la preponderancia de los intereses estadounidenses es reconocida por la oligarquía colombiana a cambio de ser ella misma reconocida, por los estadounidenses, como la clase dirigente legítima de Colombia. La docilidad con que la oligarquía colombiana acata los mandatos de los gobiernos estadounidenses es una constante histórica de su historia republicana, al menos desde las primeras décadas del siglo XX. Pero esta docilidad no puede ser gratuita: se da a cambio de la posibilidad constante y efectiva de mantener el ejercicio de su poder; en este contexto de subordinación, las asesorías estadounidenses a la oligarquía colombiana, las distintas "misiones" que se han presentado para asesorar a distintos gobiernos (Misión Kemerer, 1922, 1942; Misión Currie, 1949; misión Rockefeller, 1950; etc.), han sido una constante. Libreros y Sarmiento (2007) hacen referencia a la asesoría de Ronald Mckinnon, al gobierno de López, para 
iniciar unas reformas relativas a la banca, reformas que implicaron una liberalización del comercio exterior, así como, también, una reforma fiscal.

Éste fue el primer paso para que la oligarquía industrial, en Colombia, decayera y comenzara el auge de una oligarquía financiera, la cual, posteriormente, se unió a las oligarquías terratenientes. Con las reformas de López Michelsen se inició, pues, una nueva era para las élites, era de nuevos frentes de negocios y de alianzas; y en esta alianza entraron, entre los años ochenta y los noventa, las transnacionales. Ahora bien, el ascenso del poder económico financiero sobre el industrial, para finales de la década de los años 70, se complementó con una nueva bonanza en las exportaciones de café; pero, al mismo tiempo, con el surgimiento del narcotráfico. Este último, por un lado, presupone, como condición necesaria, un proceso de producción agrícola ilegal que implica el desarrollo de la renta de la tierra y, por otro lado, suscita el flujo de capitales hacia el sistema financiero. Cuando el presidente Álvaro Uribe, en 2004, pronunció el discurso de apertura de la negociación del TLC con Estados Unidos (Espinosa y Pasculli, 2013), afirmó una ecuación en la que equiparaba la pobreza del campo con la riqueza del "narcoterrorismo"; esta ecuación, en el discurso de Uribe, tenía una evidente relación con la política estadounidense del ATPDEA (Andean Trade Preferences for Drug Eradication $A c t$ ), que posibilitaba, durante los años noventa, preferencias comerciales para los países con problemas de producción de drogas ilícitas, con el fin de revitalizar su producción agrícola empobrecida; y, fundamentalmente, esto sólo significa la clara conciencia, en las propias oligarquías, la estadounidense y la colombiana, de que la base productiva de las drogas, es decir, el cultivo de las plantas ilícitas, se funda en la pobreza estructural del campo. En el caso particular de Colombia, para el campesino, es más rentable cultivar la planta base y producir el insumo para el narcotraficante, quien le paga en efectivo y le evita los sufrimientos que, en la comercialización de los cultivos lícitos transitorios, le comportan, por un lado, los intermediarios, y, por otro lado, la casi nula infraestructura de vías de transporte y comunicaciones entre su alejada finca y los centros urbanos de distribución. Por su parte, el narcotraficante es un empresario que se alía con grandes terratenientes que rentan del cultivo ilícito. En este punto, destella otra de las características constitutivas de la oligarquía colombiana: su alianza con poderes obscuros, ilegales, para poder establecerse en la renta de la tierra. La práctica de sostener ejércitos privados, que entran en contubernio con las fuerzas armadas del Estado, ha sido una práctica común de las oligarquías terratenientes a lo largo del siglo XX y lo que va del $\mathrm{XXI}^{5}$.

El cambio de constitución, en 1991, en el gobierno de César Gaviria — como ya lo hemos apuntado-, es el hito jurídico en este proceso de consolidación de su poder, para la oligarquía colombiana, en el nuevo contexto de la economía mundial y nacional. la Constitución Política de 1991 no tiene otro objetivo que crear las condiciones de posibilidad jurídicas para el asentamiento formal, legal y administrativo, de instituciones y procesos de política pública en consonancia total con el neoliberalismo, es decir, la tendencia del capitalismo mundial; y es que, en efecto, a nivel del capitalismo global, la necesidad de ampliar las fronteras del mercado por parte de los países productores dominantes, o sea, altamente industrializados, organizados en la OMC, induce la necesidad de acuerdos para la reducción arancelaria.

La descentralización administrativa que había comenzado, en Colombia, en los años ochenta, adquirió cuerpo jurídico definitivo con la nueva constitución política; a partir de aquí, la economía se reorientó de tal forma que la oligarquía puso sus intereses en los negocios de tercerización, reprimarización del sector productivo, la financiarización y especulación, además, por supuesto de la ya tradicional renta de la tierra. Los mandatos del Consenso de Washington dieron un piso teórico a este proceso de reorganización del poder de la oligarquía en Colombia; y el TLC es el proceso formal de inserción del aparato productivo nacional en el mercado internacional. Esto se acompaña de la reducción del Estado, de tal forma que procesos que antes estaban en poder de éste, mediante la tercerización pueden ser, luego, asumidos por empresas privadas nacionales y extranjeras: la salud, por ejemplo, es uno de los más conocidos en Colombia, por efecto de la pésima calidad de los servicios prestados a los ciudadanos promedio, calidad deplorable que contrasta con la obligación de todos de estar afiliados al sistema de salud, implicando esto una especie de impuesto que, 
del ingreso del ciudadano, se descuenta directamente a favor de estas empresas privadas. En la tercerización, el dinero público es enviado hacia las empresas privadas nacionales y extranjeras que ejecutan obras de infraestructura civiles de carácter público; de la misma forma, la flexibilización del mercado de trabajo, de empleo, posibilita la reducción de costos laborales, es decir, la disminución en la inversión de capital variable. Por su parte, las empresas de manejo de pensiones y de seguros se desarrollan como una arista de los nuevos negocios del campo especulativo en los que ha entrado la oligarquía en su nueva presentación.

Todo esto, por supuesto, acompañado del fortalecimiento de su aparato represivo y de control de los medios de comunicación. El poder de la oligarquía, en Colombia, ha estado fundado en una manera de conducir las fuerzas armadas, bajo las orientaciones de la asesoría estadounidense, fuerzas armadas cuyo desarrollo profesional interno está orientado bajo parámetros de elitización, de una forma tal que los cuadros castrenses de la oficialidad se reclutan entre las clases pudientes, es decir, la burguesía media y alta (Río, 2000). El otro pilar de su poder se halla en el control de los medios de comunicación, en particular la radio, la televisión y la prensa: aunque constitucionalmente existe libertad de expresión y de fundar medios de comunicación, la libertad de prensa, en la realidad efectiva esto sólo es realizable, plenamente, para conglomerados económicos.

\section{Los Discursos OLIGÁRQUicos SOBRE LAS BONDADES DEL TLC}

\section{Un Presidente de la República y sus Ministros}

Metodológicamente se mostrarán algunas de las declaraciones de los altos funcionarios comprometidos, directamente, con el desarrollo de la política pública del TLC. Declaraciones hechas en contextos de opinión pública, algunas, otras en contextos un poco más esotéricos, como ciertas revistas universitarias. Desde el punto de vista tecnocrático, la firma de un TLC es un proceso técnico de gran complejidad, aunque, por supuesto, la comprensión global de su intención como acto social en el que se realiza una política económica es relativamente sencilla de enunciar: realizar la libertad comercial entre naciones. La complejidad del proceso son sus determinantes jurídicas, administrativas y técnicas, desde el punto de vista económico; pero, en tanto negociación, en principio, se trata de un proceso en el que cada parte busca obtener, para sí, unos resultados beneficiosos. Un acuerdo comercial bilateral entre Colombia y Estados Unidos era una aspiración del primer gobierno propiamente neoliberal de Colombia, el de César Gaviria (1990-1994), el cual implementó, definitivamente, con el cambio de Constitución Política, el camino hacia la apertura económica. Espinosa y Pasculli cuentan — como anécdota marginal- que, en 2003, el entonces embajador estadounidense en Colombia, el señor Robert Zoellick, debió responder una pregunta inesperada del presidente Álvaro Uribe: ¿Qué es un TLC? (Espinosa, A. \& Pasculli, L., 2013, pág. 15). Esta anécdota es interesante, en tanto muestra la situación respecto del proceso en la que se encontraba el mismo presidente: el concepto de TLC, concepto importantísimo en el desarrollo de la orientación económica en curso de la nación, le era desconocido. O sea, que no era de su inmediato interés, al menos en ese momento; porque después logró darle un sentido interesante: Espinosa y Pasculli citan un fragmento de las palabras del entonces presidente Uribe en la instalación de las negociaciones, en 2004, un año después de haberse informado sobre qué es un TLC, con el embajador de Estados Unidos:

En nuestro medio, la fortaleza del sector agropecuario es la garantía de la destrucción definitiva de las drogas ilícitas. En Colombia, una agricultura débil equivale a un terrorismo fuerte. Aquí hay que impulsar plenamente la recuperación agrícola como una condición esencial para poder derrotar la droga y el terrorismo. (...) En el proceso de construcción de consenso en el país, hay que mirar también con mucho cuidado el tema regional, para que este acuerdo se suscriba con la certeza de que va a beneficiar a la Nación como un todo. (Espinosa y Pasculli, 2013, p. 8) 
La primera frase, que el sector agropecuario es la garantía de la destrucción definitiva de las drogas ilícitas, es una clara alusión al ATPDEA; refuerza esta clara alusión con la ecuación: terrorismo fuerte igual a agricultura débil; aparece el término terrorismo, substantivo que, en su jerga, hacía remisión a las guerrillas, en particular a las FARC y su poder militar. Conclusión: fortalecer el campo para derrotar el terrorismo. Luego de enterarse qué es un TLC, el presidente lo encuadró como un arma contra el terrorismo, es decir, contra las FARC, lo cual era uno de los pilares de su orientación de gobierno llamada "Seguridad Democrática". Para Uribe, el TLC con Estados Unidos era una continuación del APTDEA, y una justificación de su programa de seguridad democrática.

Este punto se aclara en la cita de las palabras del entonces ministro de hacienda, un año después de las de Uribe, en 2005:

las peculiaridades de Colombia, en particular el papel que ha venido desempeñando en la lucha contra las drogas y el terrorismo, y su carácter de socio estratégico desde el punto de vista geopolítico de los Estados Unidos, hacen de esta una negociación fundamentalmente política. (Espinosa y Pasculli, 2013, p. 9)

Las peculiaridades de Colombia: la guerra civil en el campo y su condición de "socio estratégico" de Estados Unidos, una sociedad - afirmó el ministro- desde el punto de vista geopolítico de los Estados Unidos. Por consiguiente, el TLC resultó ser una obligación de Colombia para con Estados Unidos, una obligación política. Para el gobierno del presidente Alvaro Uribe, la materialización del programa de la Seguridad Democrática se había vuelto un asunto de primer orden y es, en este sentido, como se comprende la estrategia del Tratado de Libre Comercio con los Estados Unidos. En el contexto global, el argumento de que Colombia era un aliado importante para la lucha antiterrorista de los Estados Unidos, luego de los atentados del 11 de septiembre de 2001, se convirtió en el "caballito de batalla", para que Uribe insistiera en que apoyar su programa de la Seguridad Democrática era necesario a fin de combatir el terrorismo a nivel interno y en el contexto latinoamericano; este terrorismo estaba encarnado por el grupo guerrillero Fuerzas Armadas Revolucionarias de Colombia FARC; de aquí se derivaba que la diplomacia estadounidense debía unir irremediablemente su destino al de Colombia, si quería luchar contra el terrorismo hemisférico; además, Uribe confiaba en su afinidad con el presidente G.W.Bush como garantía de una negociación bilateral, cosa que no estaba en los planes estadounidenses que siempre trataron de llevar a cabo una estrategia de negociación en bloque con los países latinoamericanos, beneficiarios del ATPDEA (Andean Trade Promotion and Drug Eradication Act). (Reinel, 2005)

En efecto, antes de la firma del TLC con Estados Unidos, Colombia tenía una relación comercial con este país en el ATPA y el ATPDEA. El primero era el Andean Trade Promotion Act, ley de los Estados Unidos que expiraba, justamente, en 2006, año de cierre de la negociación del TLC, y que había sido expedida el 4 de diciembre de 1991, quince años antes, por el presidente George H. W. Bush, en el contexto del programa estadounidense de guerra contra las drogas. Por otro lado, la segunda ley, ATPDEA, Andean Trade Promotion and Drug Eradication Act, fue otra ley, promulgada por el hijo del anterior presidente, por George W. Bush; esta ley tuvo varias renovaciones hasta que, finalmente, expiró en 2011, un año antes de la firma del Tratado por Colombia. El ATPDEA, realmente, fue otra versión de la anterior ATPA, en el contexto del mismo plan estadounidense de lucha contra las drogas en América Latina. Ahora bien, ni el ATPA ni el ATPDEA eran acuerdos, o sea, agreements, no; eran leyes unilaterales de Estados Unidos en el contexto de su guerra contra las drogas, eran acts. Leyes por medio de las cuales cedía preferencias arancelarias a países de América Latina, para suscitar, en algún sentido, el desestímulo del cultivo de insumos agrícolas para la fabricación de substancias ilícitas. Cuando llegó la negociación del TLC, éste sí un agreement, al menos técnicamente, y no un act, Estados Unidos, por medio de la negociación, con Colombia, mantuvo las preferencias de sus leyes anteriores, pero no cedió en nada más.

Ahora bien, la oligarquía y su tecnocracia presentan el TLC, en general, en términos puramente ideales, haciendo a un lado las condiciones reales. Cuando se hace necesario considerar estas condiciones reales, su 
discurso público se hace incoherente. Por ejemplo, una presentación refinada y rápida del TLC es la del ministro de comercio exterior de Álvaro Uribe, durante la negociación del TLC con Estados Unidos:

\begin{abstract}
Se va a desgravar, completamente, la importación de bienes de capital y materias primas. Como, además, el tipo de cambio es favorable para importar, lo que yo vaticino es que va a haber un flujo, muy significativo, de bienes de capital y de materias primas provenientes de Estados Unidos a Colombia. Eso va a mejorar las competitividades de muchos sectores y de muchas empresas; y se va a traducir en incrementos del volumen exportable, a mediano plazo, y en una posición competitiva mejor, para la industria nacional, en el mercado doméstico. Es como si, de pronto, hubiera el Banco de la República encontrado el mecanismo adecuado para satisfacer el anhelo de devaluar el tipo de cambio. Los ahorros que van a generarse equivaldrían a una devaluación del tipo de cambio, que sería más o menos importante según los distintos tipos de industria.

Empresarios del Brasil o de China pueden encontrar atrayente ubicarse en Colombia, finalizar los procesos de producción de una serie de productos que hoy, probablemente, no hacen parte de la oferta exportadora de Colombia; y, luego de cumplidos esos procesos de finalización del proceso fabril, exportar a Estados Unidos, gozando, bajo ciertos requisitos, de las ventajas arancelarias que tiene Colombia, en el acceso a Estados Unidos, y que no tienen ni Brasil ni China. (Botero, 2012).
\end{abstract}

En las palabras de este funcionario, el TLC es un sistema límpido y puro en el que se realiza la idea ricardiana de un comercio matemáticamente justo entre naciones. Las barreras arancelarias y cambiarias desaparecerán, y con esta desaparición, dejarán de ser relevantes las barreras o fronteras nacionales: el empresario chino o brasilero podrá producir en Colombia y hacerse un exportador desde Colombia a Estados Unidos. Un plano envidiable de cruces y relaciones, sin ninguna traba, comenzará a construirse en suelo colombiano

El TLC, presentado como un trato completamente horizontal entre iguales, por los altos funcionarios de los gobiernos, comienza a volverse un fetiche difícil de sostener a la hora de confrontar sus propiedades cristalinas con la realidad. Los funcionarios caen en omisiones, contradicciones; examinemos los ejemplos relevantes, centrados en el ministro de agricultura, la ministra actual de transporte, que fue parte del equipo negociador, y el jefe directo de la negociación entonces, que en el gobierno de Juan Manuel Santos se convirtió en el jefe de la Oficina para el Aprovechamiento de los TLC.

\title{
Actual Ministra de Transporte
}

Vamos, pues, a las palabras de la actual ministra de transporte del presidente Duque, en un conversatorio, en una universidad privada, la Universidad Externado. En su intervención, la ministra hace alusiones a la "historia", es decir, a las leyes de preferencia ATPA y ATPDEA, afirma que eran un "gran beneficio porque teníamos acceso a la mayor parte de los productos industriales" (Conferencia 6 años Balance TLC Estados Unidos - Colombia, 2018); y, por tanto, si se perdía ese beneficio, si otros llegaban antes, se hubieran visto perjudicadas las principales exportaciones a Estados Unidos, en particular una con impacto grande como las flores; Colombia no podía permitir que sus flores quedaran por fuera del mercado estadounidense. La insistencia en las flores se debe a que la ministra es miembro de la Asociación Colombiana de Exportadores de Flores. Lo que esta funcionaria de alto rango ve como diferencia entre el ATPDEA y el TLC con Estados Unidos es que el último determina reglas claras, estables e indefinidas en el tiempo, mientras que las leyes anteriores era menester renovarlas cada cierto tiempo. Lo que se obtuvo de Estados Unidos fue, según esto, la estabilidad en lo anterior que se presentaba como inestable; no hubo, pues, una renovación cualitativa, sólo una renovación formal.

La ministra afirma que le gustan los TLC porque: "si nosotros no hemos sido capaces de disciplinarnos, nosotros mismos, qué bueno que alguien nos recuerde que tenemos que ser incluyentes [...]" (Conferencia 6 años Balance TLC Estados Unidos - Colombia, 2018). En el contexto de este conversatorio, en un ámbito académico, sobre comercio global, la ministra hace una justificación ética: el TLC es formador del carácter. El TLC comporta — dice la ministra - disciplinas de transparencia, inclusión, participación, es decir, para esta funcionaria, el TLC es la realización más elaborada, hasta el momento, de la democracia en Colombia. Este ámbito democrático, la ministra lo describe en una metáfora deportiva: "si hay una carretera, y todos 
podemos correr por la carretera, pues ya depende de quién corra más, pero no tener acceso a la carretera sí sería un problema de competitividad para nosotros, nosotros lo que hicimos fue desatrasarnos frente a todos nuestros competidores [...]" (Conferencia 6 años Balance TLC Estados Unidos - Colombia, 2018). La metáfora de la carretera es interesante, en la medida en que, veladamente, permite entreverar lo real del asunto: entramos, por fin, en la competencia internacional, en el mercado, no importa sino tenemos capacidad para competir. Extraña implicación, que podría ser válida para la retórica deportiva aficionada, no profesional, en la que lo importante no es ganar sino competir; pero, en un contexto económico de relevancia nacional, tal metáfora resulta un disparate, pues aquí sí se trata siempre de ganar. Pero este disparate es, al mismo tiempo, la conciencia de la dificultad en la capacidad de competir, es decir, de lograr un intercambio mercantil.

La agremiación de las flores (representada en la ministra) logró hacer que las preferencias se volvieran indefinidas, eso era, entre otras cosas, lo importante. Otros sectores quedarán rezagados, y aún por fuera, si no logran competir. Este tema de la competencia y la capacidad para entrar en ella, por supuesto, no sólo depende de determinaciones formales, legales, sino de la capacidad real productiva de muchos sectores económicos. A seis años de celebración del tratado con Estados Unidos, los reportes sobre el aumento en las exportaciones, no son satisfactorios, y en particular, las pequeñas y medianas empresas no consiguen, todavía, entrar en la carrera (Perdomo, 2016). Ante una pregunta de la entrevistadora, en este sentido, la ministra respondió que los TLC se firman para aprovecharlos, que, por supuesto, estos acuerdos dependen tanto del Estado como del sector privado; pero el "boom petrolero" indujo a muchos empresarios abandonar el comercio exterior para dedicarse al comercio doméstico porque les resultaba más rentable: "hay decisiones empresariales que yo no juzgo, pero uno no puede culpar al TLC por eso". (Conferencia 6 años Balance TLC Estados Unidos Colombia, 2018) Interesante afirmación, dado que de lo que se trata en los negocios es de la concurrencia en la rentabilidad: empresarios que prefieren el comercio doméstico porque les representa más rentabilidad que el exterior, estable formalmente, de un TLC. Esto quiere decir que una vez se dio el TLC, estos empresarios, buscando lo que busca cualquier empresario, ganancia, se dedicaron al comercio interno, porque les es más rentable que el TLC; la ministra equipara el "boom petrolero" con el "boom del mercado doméstico", es decir, el alza en los precios de las exportaciones de petróleo diversificaron la economía interna, la reactivaron y estas empresas aprovecharon esta situación, despreciando el claro juego y la gran oportunidad del TLC; y no eran pequeñas empresas, no; eran "grandes empresas". Son alusiones crípticas, teniendo en cuenta que, por ejemplo, ciertos informes, como el del Instituto Peterson para la Economía Internacional clasificó a Colombia entre los países que no aprovecharon esa bonanza petrolera (Portafolio, 2017).

Por otra parte, la ministra afirma que la negociación del TLC con Estados Unidos no tenía la intención de tener mayor acceso a las exportaciones, porque ya se tenían por el ATPDEA, por tanto, no es de extrañar que no aumentaran las exportaciones colombianas, era esperable. La condición para que aumenten, en las condiciones presentes, afirma la funcionaria, es la diversificación productiva (Conferencia 6 años Balance TLC Estados Unidos - Colombia, 2018). Esto indica que las élites comerciales que negociaron el TLC con Estados Unidos, estaban asegurando sus ventajas que resultaban intermitentes con la situación anterior, pero para ello, por supuesto, se vieron obligadas a comprometer un acuerdo general que, formalmente, abre las puertas para todos los otros rubros productivos, aunque no sean capaces de integrarse en ese acuerdo. Ahora bien, como el acuerdo de libre comercio es bilateral, las ventajas han de darse de ambos lados: la ministra aclara que si bien no han aumentado las exportaciones, sí lo han hecho las importaciones: "lo que sí iba a pasar era que iban a crecer las importaciones y no necesariamente porque importáramos más: era porque íbamos a sustituir orígenes [..]" (Conferencia 6 años Balance TLC Estados Unidos - Colombia, 2018). Afirmación obscura, casi sibilina ésta: aumentan las importaciones pero no porque se importe más que antes, o sea, aumentan pero no porque aumenten. En conclusión, no aumentaron las importaciones tampoco, como no lo hicieron las exportaciones, lo que ocurrió es que se sustituyó la fuente de la importación; aclara con un ejemplo concreto: se tenían preferencias con Brasil, recibiendo sus insumos petroquímicos, pero luego se desplazó a Brasil a favor de Estados Unidos. La ministra, a cada frase, deja en claro que el TLC con Estados Unidos no fue más que 
devolver un favor a Estados Unidos, por las preferencias cedidas anteriormente en el ATPDEA y el ATPA, preferencias que beneficiaban a los grandes empresarios cultivadores de café, banano y flores, un sector de la oligarquía agraria a la que pertenece la misma funcionaria. Finalmente añade: "uno no puede medir un TLC simplemente por el balance de déficit o superávit" (Conferencia 6 años Balance TLC Estados Unidos - Colombia, 2018). Frase más obscura aún que las anteriores: pese a que el TLC es la formalización de un acuerdo comercial bilateral, o sea, un asunto de negocios y ganancias y rentabilidad; sin embargo, el déficit o el superávit no pueden ser los criterios de evaluación; por tanto, no se trataba, con este TLC de aumentar exportaciones, ni siquiera importaciones, se trataba de dar privilegios a las exportaciones estadounidenses.

Pero la conciencia de esta situación se expresa de otras formas, en particular en el asunto de la pregunta por las fortalezas que no tiene la débil economía colombiana para hacer frente a la estadounidense, pues, dada la asimetría de principio ¿cómo conjurar, entonces, la consecuente repartición asimétrica de los beneficios? El punto está, entonces, en cómo nos hacemos fuertes. Este punto de fortalecerse tiene que ver, concretamente, con cómo producir más, y cómo superar las barreras no arancelarias, las cuales implican, de principio, el control de la calidad de los productos. Un tema tecnológico. Sobre esto, la ministra responde con que ya era sabido, desde un principio, que las barreras no arancelarias serían, efectivamente, un obstáculo:

[...] ]eso exigía que el sector privado destinara grandes recursos a hacer los estudios, a contratar las universidades, etc., digamos, yo sí tengo que ser franca: aquí la discusión en el sector agrícola siempre se dio de mantener un sistema de subsidios directos al bolsillo de los agricultores [...] la teoría que yo siempre tuve es que, desde el punto de vista privado, lo importante luego era contratar los estudios para lograr, de alguna manera, el impacto que generara en todos un flow, es decir, que tuviera un spill over sobre todos los de un sector, y es decir, cómo transformar los subsidios directos hacia bienes públicos [...] Ésa es una discusión no puntual, ésa es una discusión de país: qué pasa con los bienes públicos, lograr la admisibilidad es un bien público; y exige tanto la diplomacia comercial y recursos del Estado, como exige que el sector privado le diera prioridad a una agenda y dijera 'vamos a hacer convenios con X universidades, vamos a lograr la admisibilidad en tal y en tal y en tal, vamos a contratar porque aquí hay mucha gente que puede hacer eso [...] el ICA fue ejemplo en América Latina, fue una entidad que dejaron ir politizando cada día más; y lo que había que fortalecer era el ICA y el INVIMA; pero no es sólo culpa del gobierno, a mí me disculpan ustedes [...] ¿ dónde están los gremios para exigir [que estas entidades] sean técnicas? ¿dónde están los gremios que apoyan las campañas políticas para decirle a sus congresistas que no pueden ser políticas este tipo de entidades? [...](Conferencia 6 años Balance TLC Estados Unidos - Colombia, 2018)

Largo lamento el de la ministra, por la desidia ética de los gremios en contubernio malsano con los políticos corruptos. Esta ignominiosa situación, dice, da al traste con la posible estrategia de una combinación de dinero público y privado, que solucionaría el problema tecnológico. Pero la terrible verdad de una desunión del interés nacional, del país, ha conducido a la politización de las entidades del Estado - como el ICA (Instituto Colombiano Agropecuario) - cuya misión es ser entidades de apoyo técnico, científico, a las políticas públicas. Cuánto dinero ha de ir directo del Estado al agricultor, cuánto dinero ha de destinarse a obras de infraestructura y procesos técnicos, por qué no va más a estos que a aquéllos, por qué se han dejado politizar instituciones que no debían politizarse, etc. En este lamento, el aspecto de fortalecimiento de la producción se confunde, la pregunta por la técnica, la base real de la producción, se transforma en lamentos sobre la tacañería del sector privado y la politiquería y corrupción del sector público, es decir, la debilidad técnica es un asunto moral. La incapacidad técnica disimulada como incapacidad ética; así, las bondades económicas del TLC con Estados Unidos, prometidas pero no cumplidas, dependen de la conciencia moral debilitada de los empresarios colombianos, si ésta es inexistente, esas bondades no se harán manifiestas.

\section{Un Ministro de Agricultura}

En general, las declaraciones que se pueden recoger, en diversos medios, de los altos funcionarios legitimando, tanto la decisión de suscribir el TLC con Estados Unidos, como sus inocuos resultados, en términos de lo que se promete al suscribirlo, todas ellas apelan al sentido moral. Esta constante apelación al sentido moral deja entrever una impotencia, la cual se hace más clara cuando las declaraciones ya no se dan en 
contextos de discurso informal sino que, por razón del contexto, como lo es el contexto de la ciencia misma, las declaraciones han de volverse un poco más rigurosas. A un año de la firma del tratado, en 2013, el ministro de agricultura de Álvaro Uribe, en el último año de su primer período de gobierno (de 2005 a 2006), y que tuvo bajo su responsabilidad la negociación desde el ministerio de agricultura, escribió sobre las onerosas condiciones en que se firmó el TLC con Estados Unidos, la cautela que se debe tener en próximos tratados, en especial con los grandes Estados asiáticos y lo promisorio que puede resultar, en el futuro, para Colombia, la subida, a nivel mundial, de los alimentos e insumos de origen agrícola. Respecto de las pésimas condiciones del TLC, para Colombia, con Estados Unidos, afirmó el exministro:

[...] en el tratado con Estados Unidos de los tres pilares de las negociaciones -el libre acceso a los mercados, la eliminación de los subsidios a las exportaciones, y la supresión de las ayudas internas a los agricultores-, solo con respecto a los dos primeros se podía alcanzar acuerdos. De ahí el reclamo expresado por parte del Ministerio desde la iniciación de las negociaciones de mantener medidas de protección en frontera equivalentes, a fin de anular o reducir a su mínima expresión la volatilidad y el efecto distorsivo sobre los precios internacionales de las ayudas internas, en tanto éstas subsistieran. El Sistema Andino de Franjas de Precios (SAFP) fue una herramienta que cumplía a cabalidad con este objetivo. Nunca fue demandado ni cuestionado en los términos que dictan las normas vigentes en el comercio internacional agropecuario, y, por tanto, gozó de legitimidad ante la OMC. Pero a la postre no se mantuvo, ni fue sustituido por un instrumento equivalente. He ahí la mayor fuente de vulnerabilidad a la que quedó expuesto el sector. De igual manera, el Ministerio estuvo empeñado en buscar un compromiso de parte de Estados Unidos de eliminar ante la OMC sus ayudas internas antes de la finalización de los distintos períodos de transición pactados en el tratado. Sin embargo, ni su supresión, ni siquiera su reducción, hacían parte de la agenda de las negociaciones bilaterales de la nación norteamericana, limitándose sus discusiones únicamente a los otros dos pilares. Esto es, acceso a mercados y subsidios a las exportaciones. Finalmente, se propuso una 'fórmula de salvamento' materializada en mecanismos de estabilización de precios iguales, similares o equivalentes al sistema de franjas; derechos anti dumping automáticos; derechos compensatorios; aranceles específicos; contingentes arancelarios; cláusulas automáticas de salvaguardia especial; o combinaciones de tales instrumentos, que operara después del lapso aludido en caso de que las importaciones provenientes de Estados Unidos - en especial las de arroz, maíz, soya, fríjol y pollo- continuaren llegando con precios por debajo de sus reales costos de producción, efecto directo de tales ayudas internas, y en volúmenes que amenazaren o pudieren causar grave daño a la producción y el empleo rural nacional [...]. Sin embargo, ninguna de tales alternativas se adoptó en ningún otro tratado bilateral previamente culminado por parte de otras naciones latinoamericanas, creando un complicado precedente para todos los tratados posteriores, entre ellos el acordado con Colombia, que concluyó sin ninguna cláusula que previera tal situación. (Cano, 2013, p. 65)

Esta larga cita es necesaria para apreciar lo que piensa uno de los economistas asesores naturales del gobierno, pues era el mismo ministro de agricultura en la negociación. Sus palabras son interesantes, porque da cuenta de lo que no se logró y debía haberse logrado, lo que era responsabilidad de su equipo de negociadores lograr: mantener el sistema andino de franjas de precios; que Estados Unidos eliminara las ayudas internas; establecer mecanismos de estabilización de precios, etc. El lenguaje del exministro es, gramaticalmente, interesante porque, al referirse a aquellas cosas que se debían lograr y no se lograron, emplea el impersonal: el sistema de franjas de precios "no se mantuvo"; ninguna de las alternativas "se adoptó"; ni la reducción o supresión de las ayudas internas "hacian parte de la agenda”. Huelga decir, por supuesto, que es una moda editorial, en nuestras revistas criollas, solicitar a los autores la redacción en este estilo impersonal bajo el ingenuo argumento de que así se mantiene la objetividad, como si ésta fuera un efecto de estilo narrativo. Sin embargo, también, en este caso, el caso del exministro y su artículo, ese estilo impersonal no sólo responde a una demanda editorial, sino que facilita, entre otras cosas, evadir la responsabilidad: las cosas no se dieron. Todo queda como si el evento de la negociación — con todo y lo "competentes" que eran los miembros del equipo negociador - hubiese corrido al garete de una dinámica que no dependía de los miembros del equipo negociador, como si la negociación tuviese sus propias leyes independientes de las partes negociadoras. Ese estilo impersonal no sólo cumple las exigencias baladíes de la revista que recibe el artículo, también permite encubrir un "no queríamos contradecir a los estadounidenses".

El exministro, un tecnócrata economista, por supuesto, tiene fe en las bondades del tratado de libre comercio, piensa que no se debe renunciar a la persistencia "en la senda multilateral como la opción óptima para la agricultura” (Cano, 2013, p. 66), es decir, en futuros TLC, en particular con países desarrollados del 
Asia extrema, como Korea del Sur y Japón, que, al igual que Estados Unidos, mantienen una protección interna a su agricultura; extraña fe esta la que lo induce a pensar que esas potencias del oriente extremo desprotegerán, en un futuro, su economía agrícola, protección que les ha permitido ascender como tales naciones poderosas. Esa fe no puede explicarse más que como un corolario moral, una especie de mea culpa o algo parecido que, estilísticamente, matiza las confesiones vergonzantes hechas en la mayor parte del escrito.

\section{Un tecnócrata de Alto Coturno}

El TLC con Estados Unidos (un tanto adverso a la ganadería) fue negociado en el primer gobierno de Álvaro Uribe (él mismo un reconocido ganadero), cuatrienio de gobierno que corrió de 2002 a 2006; y entró en vigencia en el primer gobierno de Juan Manuel Santos (2010 - 2014). Examinemos lo que dice el Director de la Oficina de Aprovechamiento de los TLC, organismo burocrático creado por el gobierno de Juan Manuel Santos. Este funcionario fungió, a su vez, como jefe de las negociaciones con Estados Unidos en el gobierno anterior al de Santos, es decir, en el Gobierno de Álvaro Uribe; en una entrevista para una revista de opinión pública, manifestó que el TLC es un acuerdo "histórico"; no le faltaba razón al hacer la afirmación, el problema fueron los argumentos con que la sostuvo. Primero, que el TLC cambiaría "las posiciones a favor de Colombia respecto al mercado de los Estados Unidos, a donde van la mitad de nuestras exportaciones." (Gómez H. J., 2006); posiciones que no iban a cambiar por las asimétricas condiciones respectivas entre los dos países y que, de hecho, no han cambiado. Añadió, además, lo siguiente: que en tres años, luego de la firma del Tratado, las exportaciones de Colombia aumentarían en 50\% "Por la cantidad de preferencias arancelarias, por la consolidación del Atpdea. Por la cantidad de sectores que van a tener esas preferencias [...] Habrá un incremento de la capacidad productiva." (Gómez H. J., 2006) La cantidad de preferencias arancelarias a las que alude, se deduce, es una cantidad enorme, lo cual hará aumentar las exportaciones en el 50\%. El ATPA y ATPDEA quedaron subsumidos en el TLC, fue lo único que consiguió Colombia; pero eso no fue una novedad, eso ya estaba. Así que, cuando el jefe del equipo negociador, contestó a las preguntas del entrevistador, de forma grandilocuente, el triunfo de Colombia, estaba exagerando. Por supuesto, se sobreentiende la exageración, pues daba declaraciones a un medio de opinión pública, una revista de amplia circulación y de aparición semanal. Por tanto, terminó de dorar la píldora mediática afirmando, luego, que sería necesario otorgar ayuda a los cultivadores de arroz, maíz y avicultores, lo cual, por supuesto, implica que la situación para estos gremios se pondría difícil. Pero lo más interesante ocurre en su última afirmación, acerca de las cosas en las que cedieron los Estados Unidos:

La carta adjunta en materia sanitaria fue de las más difíciles de lograr. Lo mismo la carta adjunta para el respeto a la biodiversidad, que es de vital importancia para este país [...] Logramos en el caso del arroz que entre en un precio más razonable para que pueda competir con el colombiano. (Gómez H. J., 2006)

Considera un logro de Colombia el que el arroz de Estados unidos pueda competir con el colombiano; extraño logro, como si un técnico de un equipo de fútbol considerara un logro hacer que el equipo contrario, en vez de ser mantenido a raya, pudiera acercarse con peligro, e incluso anotar, en su propia cancha, la del equipo del técnico en cuestión. El logro ha debido ser, en la lógica del negocio, que el arroz estadounidense no hubiera podido competir con el colombiano; esto hace más insidiosa la sospecha de que el TLC era una concesión a Estados Unidos.

En un contexto no mediático, a un año de la firma del TLC, Gómez publicó, en una revista académica, un resumen de los logros de su oficina de aprovechamiento de los TLC; en este resumen, informó sobre las acciones que se llevaron a cabo, a partir de consultas con los gremios. Curiosamente, todo el texto se refiere a las acciones que se tomaron; $y$ al final presenta unos resultados relativos al aumento de las exportaciones al cabo del año de la firma del acuerdo. Pero los resultados son presentados en gráficas crípticas en cuyas barras de colores que ascienden, de un año al otro, no se puede saber qué rubros representan, aunque sí se 
puede saber los que no representan: petróleo, carbón, esmeraldas, café, flores y banano (Gómez H. J., 2013) productos que ya venían exportándose en cantidades beneficiosas antes del tratado y cuya protección fue el objeto de la negociación; pero los que se incrementan por el tratado, es decir, los que habrían de empezar a ser exportados masivamente luego una vez entrado en vigencia el tratado, los resultados quedan ocultos, mudos, en el misterio.

No obstante, este misterio se puede resolver en las declaraciones del funcionario en una entrevista transmitida en vivo, en un portal de internet de un periódico nacional especializado en temas económicos: allí vuelve a referirse a los consabidos temas de cómo hacer para que se eleve el volumen de exportaciones debido al hecho de que se requiere que los empresarios aprovechen las condiciones formalmente favorables para la exportación. Cabe decir que la existencia de tal oficina del gobierno, que dirige este alto funcionario, la oficina para el aprovechamiento de los TLC, es la expresión de que el gobierno ha de crear las garantías para que, de alguna forma, la burguesía nacional, grande y pequeña, se articule en el comercio internacional; y, en este sentido, el funcionario afirma que su oficina es un ente estatal de articulación entre las diversas instancias que harán posible tal proceso. Una oficina para el aprovechamiento, o sea, el TLC debe ser aprovechado, pero este aprovechamiento, o sea, esta actividad económica suscitada gracias a la firma de un acuerdo comercial, no se da por sí mismo, como sería los esperable en términos de la propia economía política clásica que sostiene que los individuos buscan realizar su beneficio. No; el gobierno tiene que inducir en ellos el aprovechamiento de la oportunidad de negocios; por tanto, tales beneficios derivados de la firma del acuerdo comercial no resultan una evidencia de principio. Esto confirma el carácter inconveniente, para la propia mayoría de empresarios, de tal acuerdo.

Ahora bien, afirmó el funcionario, en el contexto de la entrevista en el programa, respecto de los sectores que pueden aprovechar esas ventajas formales del TLC: "indudablemente, las grandes empresas colombianas todavía pueden exportar muchísimo más; sí, la verdad es que no estamos utilizando sino una mínima parte del acceso preferencial que tenemos a mercados internacionales [...]”. (Hernando José Gómez/Zar de TLC con EEUU, 2013)

Es preciso afirmar que esta afirmación la hizo el funcionario un año después de que entró en vigencia el tratado: un años después aún las grandes empresas no lo habían asumido plenamente. Las grandes, o sea, las que, en principio tienen la capacidad productiva y logística suficiente. No sabemos si entre esas grandes empresas, el funcionario contaría las bananeras, cafeteras y de floricultura. Sin embargo, sí nos ilustra acerca de ciertas empresas que para ese año ya habían comenzado a exportar:

Yo tengo mucha fe que el sector agropecuario puede ganar inmensamente con estos tratados de libre comercio ... hicimos una priorización de productos...ępor qué no se siembra la piña gold en Colombia? Porque, realmente, teníamos otras especies, había un problema de acceso a la semilla ... pero ya tenemos, por lo menos, dos grandes grupos empresariales ... eh.. tres grupos empresariales que empezaron a sembrar piña golden en el Cesar, en el Urabá y en el norte del Valle... a la vuelta de un año vamos a empezar a ver exportaciones muy interesantes de piña golden a la Unión Europea y a Estados Unidos. (Hernando José Gómez/Zar de TLC con EEUU, 2013)

En la priorización de productos no parece tener un lugar destacado, por el momento, la carne. Pero sí la piña golden. ¿Cuál puede ser el criterio de esa priorización? Estados Unidos es un gran productor de carne, aunque la carne está dentro de los productos promisorios, para Colombia, en el TLC con Estados Unidos. ¿Cómo competir con este gran productor de carne? Por supuesto, no es menester ser injustos: la carne bovina colombiana, recientemente, ha entrado al mercado estadounidense, aunque en pequeña proporción en relación con otros mercados extranjeros. Por ejemplo, anunció el portal de internet procolombia, especializado en el TLC Colombia-Estados Unidos, que en 2015, del 100\% de la carne exportada, el 3\% fue enviada a Estados Unidos. Es, no obstante, una cantidad muy pequeña, para haber sido la carne uno de los productos promisorios.

Es comprensible por qué, al examinar las palabras del alto funcionario del TLC en Colombia, se descubre que éste declara como un gran triunfo el comienzo de la siembra de la piña Golden: a diferencia de la carne 
bovina, la piña no es un alimento básico, sino suntuario; los protocolos de admisibilidad los ha obtenido, primero, la piña Golden que la carne, lo que es comprensible, pues Estados Unidos no produce frutas tropicales. Ahora bien, los grupos empresariales a los que se refiere el funcionario venden la piña Golden sin valor agregado, es decir, la venden fresca. ¿Cuáles son esos grupos? “[...]Se que [...] no se si estén felices de que uno los mencione con nombre propio, pero grupos bananeros en Urabá están sembrando piña Golden, eh... hay un grupo de la zona cafetera con eh...con el grupo Efromovich, en el Cesar; Riopaila está trabajando en el norte del Valle [...]”.(Hernando José Gómez/Zar de TLC con EEUU, 2013)

Esos grupos, que ahora se dedican a la siembra de la piña tropical Golden, son, evidentemente, grandes compañías que están reinvirtiendo ganancias en otros rubros como el banano y el azúcar. Son compañías financieramente fuertes, ubicadas en lugares de conflicto: Urabá, Cesar, Norte del Valle. Este detalle permite destacar dos situaciones implícitas en el TLC: una, las compañías que pueden aprovechar sus ventajas comerciales, son aquellas que pueden reinvertir ganancias en estos rubros en los que, efectivamente, no cabe la competencia, en términos de producción con Estados Unidos; pero esto significa, a su vez, que se cede al monopolio de Estados Unidos sobre productos básicos de alimentación; por tanto, el tratado de libre comercio, lejos de ser el acuerdo democrático entre iguales, es la repartición de mercados bajo el criterio de la capacidad del poder productivo, o sea, del más fuerte; pero el más fuerte, en términos agrícolas es el que puede controlar los alimentos básicos; así, como lo afirma Rubio (2015), Estados Unidos ha logrado mantener su hegemonía económica sobre Latinoamérica en particular en la medida en que logra dominar la producción de los alimentos básicos a través del capital financiero.

El aprovechamiento del TLC, de acuerdo con el director de la oficina, no sólo consiste en la detección de los frentes de demanda externos, sino en la cualificación en relación con el proceso de producción.

\section{ConcLusión}

El lastre que pesa en la retórica de los tecnócratas y políticos que intentan justificar el TLC entre Colombia y Estados Unidos, en condiciones desventajosas para Colombia, es el mismo que pesa para cualquier retórica: la realidad. Ésta hunde, en la inconsistencia, el tejido argumental de las declaraciones mediáticas y aun las académicas. El TLC es siempre, presentado, públicamente, como un logro democrático entre pares, dos países soberanos que hacen un tratado. Pero al evidenciarse que la competencia está determinada, desde un comienzo, por el poder abrumador de la producción estadounidense, la conciencia oligárquica enroca, como en el ajedrez, poniéndose, entonces en la casilla de la ética: el emprendimiento, la conciencia moral de los gremios y los políticos, la lección para ser más cautelosos en futuros TLC, lo saludable que resulta, para la formación de la conciencia nacional, que otro nos resalte nuestras debilidades; la necesidad de educar a los empresarios para que aprendan a ubicar las oportunidades y aprovechen de la mejor manera el tratado que el Estado les ofrece.

Abroquelarse tras el baluarte moral, incluso llegando al posible reconocimiento de un error, ayuda a encriptar el interés real: mantener los privilegios que un sector agrario ya tenía desde antes; este sector puede, luego, reinvertir sus ganancias en rubros que no le interesa producir a los estadounidenses, como las frutas tropicales. Pero, entonces, una vez que el capital dinero puede invertirse en este rubro, hacerlo competitivo requerirá establecer la cadena productiva del agronegocio: subordinar al campesinado en la política del desarrollo rural; pacificar los territorios en conflicto, bien con el paramilitarismo, bien con la alianza y asesoría militar de los Estados Unidos, en el Plan Colombia y el Plan Patriota, o bien con el diálogo con la fuerza armada contendiente: la paz adquiere su significado real: la tranquilidad para los agrocultivos y la exploración minero energética; y el posconflicto, la otra política pública simultánea con el TLC, muestra su sentido como el período de total eliminación del obstáculo que estorba la inversión extranjera y el desarrollo de los agronegocios. Con el TLC, la oligarquía colombiana contemporánea consolida su moderna forma de ejercer el poder en el Estado. 


\section{REFERENCIAS}

Cano, C. G. (2013). La Agricultura Colombiana de Cara a los Pactos Bilaterales de Comercio. Revista de Ingeniería Universidad de los Andes, 63 - 70.

Conferencia 6 Años Balance TLC Estados Unidos - Colombia. (2018). [YOUTUBE] Bogotá. Disponible en: https:// www.youtube.com/watch?v=n38nfE91 rrk; [Accessed 4 August 2018]

Dillon, J. (1995). Bases teóricas y prácticas de los tratados de Libre Comercio ALC/TLCAN/GATOMC. Revista de la Fundacao de Economia e Estadistica FEE, 279 - 305.

El Exministro de Comercio Exterior, Jorge Humberto Botero, Habla sobre el TLC. (2012). [Youtube]. Bogotá. Obtenido de https://www.youtube.com/watch?v=PSUML8mRNms\&t=52s

Espinosa, A. y Pasculli, L. (2013). Visión Agricola del TLC con Estados Unidos: preparación, Negociación, implementación y aprovechamiento. Santiago de Chile: Naciones Unidas-CEPAL.

Estrada Alvarez, J. (2006). Las Reformas Estructurales Y La Construcción Del Orden Neoliberal En Colombia. En A. E. Ceceña, Los desafios de las Emancipaciones en un Contexto Militarizado (págs. 247 - 248). Ciudad Autónoma de Buenos Aires: CLACSO.

Garay, L., Barbieri, F., \& Cardona, I. (2010). Impactos del TLC con Estados Unidos sobre la Economía Campesina en Colombia. Bogotá: ILSA.

Gómez, H. (26 de abril de 2012). Nos Vamos a Sorprender de Tantos Negocios Nuevos. (A. F. Ramírez, Entrevistador) Obtenido de http://www.elmundo.com/portal/noticias/economia/nos_vamos_a_sorprender_de_tantos_neg ocios_nuevos.php\#.W_idEegzbIV

Gómez, H.J. (2 de Febrero de 2006). "El TLC Mejorará la Posición de Colombia": Hernando José Gómez. (ONLINE, Entrevistador) Recuperado el noviembre de 2018, de https://www.semana.com/on-line/recuadro/el-tlc-mejor ara-posicion-colombia-hernando-jose-gomez/128767-3

Gómez, H. J. (2 de agosto de 2012). El Talón de Aquiles del TLC es la Infraestructua: Zar. (E. Negrete, Entrevistador) Obtenido de http://confidencialcolombia.com/tlc/el-talon-de-aquiles-del-tlc-es-la-infraestructura-zar_2005 $31 / 2012 / 08 / 02 /$

Gómez, H. J. (2013). Avances y Perspectivas del Aprovechamiento del Tratado de Libre Comercio con Estados Unidos. Revista de Ingeniería. Universidad de los Andes, 60 - 62.

Hernando José Gómez / Zar De TLC con EE.UU. (2013). [Youtube]. Bogotá. Retrieved 2 August 2018, from http s://www.youtube.com/watch?v=12dBMd6kl_w

José, E. J. (2005). Élites, intelectuales y tecnocracia. Calidoscopio contemporáneo y fenómeno latinoamericano actual. Colombia Internacional 26, 100 - 119.

Lafaurie, J. F. (3 de Julio de 2015). Crédito Agropecuario III: las comparaciones. Obtenido de CONtexto ganadero: ht tps://www.contextoganadero.com/columna/credito-agropecuario-iii-las-comparaciones

Libreros D., Sarmiento L. (2007). La Hegemonía de la Oligarquía Financiero-Terrateniente en Colombia. Revista Espacio Critico., 20.

Marx K y Engels, F. (1987). La ideología alemana. México D. F.: Grijalbo.

MINCIT. (2019). Comercio Exterior Colombiano: Seguimiento a los Acuerdos Comerciales. Bogotá: Gobierno de Colombia. Obtenido de http://www.mincit.gov.co/getattachment/estudios-economicos/seguimiento-tlc/segu imiento-vision-nacional/acuerdos-comerciales-vigentes/oee-lvh-seguimiento-av-dic19.pdf.aspx

Perdomo, M. (2 de noviembre de 2016). jorgerobledo.com. Recuperado el 21 de agosto de 2019, de https://jorgeroble do.com/las-cifras-del-tlc-con-estados-unidos-confirman-su-fracaso/

Portafolio. (15 de febrero de 2017). Colombia, entre los países que menos aprovecharon el "boom" petrolero. Portafolio. Obtenido de https://www.portafolio.co/negocios/colombia-no-aprovecho-auge-petrolero-503429

Reinel, J. (2005). La Estrategia de Uribe de negociación del TLC. Colombia Internacional, 12-32.

Río, C. T. (2000). Fuerzas Armadas y Seguridad Nacional. Bogotá : Planeta .

Rubio, B. (2015). El dominio del hambre. Crisis de hegemonía y alimentos. México: Juan Pablos Editor. 
Sosa M. y Posada M. (2018). El Impacto del Tratado de Libre Comercio entre EEUUy Colombia para el Comercio del Sector Agropecuario (2007-2017). Tesis de grado, Medellín.

Suárez, A. (2015a). Efectos del TLC Colombia-EEUU sobre el agro. Los Rostros. Bogotá D. C.: OXFAM y Planeta Paz. Villoro, L. (1982). Creer, Saber, Conocer. México D. F.: Siglo XXI.

Villoro, L. (1985). Del Concepto de Ideología. En L. Villoro, El Concepto de Ideología y Otros Ensayos (págs. 15 - 40). México D. F.: Fondo de Cultura Económica.

\section{Notas}

1 Entre estos productos promesa están: uchuva, piña, maracuyá, mango, bananito, feijoa, granadilla y tomate de árbol; algunas hortalizas: ají, cebolla bulbo, brócoli, coliflor, lechugas gourmet, alcachofa y cultivos de tardío rendimiento: cacao, caucho, macadamia y marañón; de ciclo corto: papa amarilla, tabaco, algodón y ganadería bovina de carne; actividades piscícolas, como el camarón de cultivo y la tilapia; la producción de insumos para biocombustibles (Garay, Barbieri, \& Cardona, 2010)

2 Aquí no cuenta el café, el banano, ni las flores pues previo al TLC, estos ya tenían ventajas arancelarias y se exportan a Estados Unidos.

3 Hay, no obstante, apellidos que se saben de linajes adscritos exclusivamente al sector empresarial como, por ejemplo, Ardila, Santo Domingo, Sarmiento, que aunque sin un ejercicio directo de cargos políticos, están íntimamente imbricados con la oligarquía política.

4 El Frente Nacional fue un sistema político de turnos alternativos, de control del gobierno, entre las oligarquías adscritas a los sendos partidos políticos dominantes durante la casi totalidad del siglo XX en Colombia, el liberal y el conservador; este sistema de turnos fue vigente entre los años 1958 (inicio del gobierno de Alberto Lleras Camargo) y 1978 (fin del gobierno de Alfonso López Michelsen).

5 En la última década en especial se ha producido una literatura, entre académica y periodística, especializada en tratar de estudiar el vínculo entre grupos del crimen organizado y las oligarquías. Entre los ejemplos recientes están: Cepeda, I \& Rojas, J. A LAS PUERTAS DEL UBÉRRIMO. TESTIMONIO, DEBATE, 2009./ López, Claudia (editora) Y REFUNDARON LA PATRIA...De cómo mafiosos y políticos reconfiguraron el estado colombiano. Corporación Nuevo Arcoiris, DEBATE, Primera edición, agosto de 2010, primera reimpresión septiembre de 2010./ Aranguren, M. MI CONFESIÓN. AUTOBIOGRAFÍA DE CARLOS CASTAÑO. Editorial Oveja Negra. 11ª edición, 2013./ Cepeda, I. \& Uribe, A. Por las Sendas de EL UBÉRRIMO. B. Grupo Zeta, 2014./ Estrada, J. ACUMULACIÓN CAPITALISTA, DOMINACIÓN DE CLASE Y REBELIÓN ARMADA. Elementos para una interpretación histórica del conflicto social y armado. En: CONTRIBUCIÓN AL ENTENDIMIENTO DEL CONFLICTO ARMADO EN COLOMBIA. Comisión histórica del conflicto y sus víctimas, ediciones desde abajo, 2016, pp 295 - 358./Tobón, Gilberto, ESTADO, POLÍTICA Y ECONOMÍA EN COLOMBIA -Capitalismo burocrático y Gansteril. SEÑAL EDITORA, 2018.

* Este artículo de investigación forma parte de la tesis doctoral titulada: Neoliberalismo En El Campo Colombiano: Ser Campesino (Colono) En El Siglo XXI. El Caso De Las Comunidades Campesinas De Los Parques Nacionales Naturales Tinigüa Y Cordillera Los Picachos En El Marco Del Posconflicto dirigida por el Doctor Adrian Serna Dimas, desarrollada en la línea de investigación memoria, Experiencia y Creencia del Grupo Vivencias del Doctorado en Estudios Sociales de la Universidad Distrital Francisco José de Caldas. (proyecto no financiado)

\section{BY-NC-SA}

